Brit. Heart J., 1964, 26, 116.

\title{
THE HEART-LUNG COEFFICIENT AND THE TRANSVERSE DIAMETER OF THE HEART
}

\author{
BY \\ NAIRN R. COWAN \\ From the Consultative Health Centre for Older People, Rutherglen, Lanarkshire, Scotland \\ Received March 23, 1963
}

The purpose of this paper is to define the influence of age on the heart-lung coefficient (Kerley, 1950) throughout life in a healthy population group, and to show that the heart-lung coefficient is as efficient as the transverse diameter of heart in the estimation of heart size.

\section{SubJeCtS AND Methods}

The data are derived from the records of 3339 male and 3650 female subjects within the age range from infancy to 89 years, who attended either the Consultative Health Centre for Older People or the Rutherglen Chest Clinic of the Western Regional Hospital Board over a period of six years. Subjects were excluded from this series where there was disease, pregnancy, asymmetry of the chest, or difficulty in making accurate measurements: in addition subjects over the age of 54 years who were 25 per cent or more over the ideal weight as estimated from Anderson's nomogram (1948) were excluded.

The heart-lung coefficient is the maximum transverse diameter of the heart divided by the maximum transverse diameter of the chest. The transverse diameter of the heart was measured as previously described (Cowan, 1959). The transverse diameter of the chest is the horizontal distance between the internal surfaces of the ribs on the right and left sides, superior to the costal attachment of the diaphragm at that point where the width of the chest is greatest. Measurements were recorded to the nearest millimetre from x-ray films taken in the postero-anterior position at a distance of 2 metres over the age of 1 year, and at a distance 1.25 metres in infancy.

\section{RESULTS}

Table I shows for male and female subjects the means, with their standard errors, of the heart-lung coefficient and transverse diameter of heart by yearly age-groups to 19 years and thereafter by fiveyear age-groups.

A logarithmic transformation of the heart-lung coefficient means is presented in Fig. 1 to show the relative changes with age.

Table II gives the 95 per cent limits of the observations by age and sex for the heart-lung coefficient.

Heart-Lung Coefficient. Except for ages 3 and 11 years, the heart-lung coefficient means of the female subjects are all greater than the corresponding means for the male subjects. Girls show a decline, which may be regarded as inherently non-linear, in average values from 0.516 in infancy to 0.427 at 19 years. A phase of little change then exists until 40-44 years. From the average of 0.445 at $40-44$ years there is fairly regular increase in the means to reach a maximum value of 0.539 at $85-89$ years.

The male heart-lung coefficient means follow a similar course to that of the female up to the age-group 35-39 years. The average values for male subjects at infancy, 19 years, and 35-39 years 
TABLE I

Means of Heart-Lung Coefficient and Transverse Diameter of Heart by Sex AND BY YeARly Age-Groups TO 19 YeARS AND THEREAFTER BY FIVE-YEAR AgE-GROUPS

\begin{tabular}{|c|c|c|c|c|c|c|}
\hline \multirow[t]{2}{*}{$\begin{array}{l}\text { Age-group } \\
\text { (yrs.) }\end{array}$} & \multicolumn{2}{|c|}{ Number } & \multicolumn{2}{|c|}{$\begin{array}{l}\text { Heart-lung coefficient } \\
\text { means } \pm S . \mathrm{E} \text {. }\end{array}$} & \multicolumn{2}{|c|}{$\begin{array}{l}\text { Transverse diameter of heart } \\
\text { means } \pm \text { S. E. } \\
(\mathrm{cm} .)\end{array}$} \\
\hline & Male & Female & Male & Female & Male & Female \\
\hline $\begin{array}{c}<1 \\
1 \\
2 \\
3 \\
4 \\
5 \\
6 \\
7 \\
8 \\
9 \\
10 \\
11 \\
12 \\
13 \\
14 \\
15 \\
16 \\
17 \\
18 \\
19 \\
20-24 \\
25-29 \\
30-34 \\
35-39 \\
40-44 \\
45-49 \\
50-54 \\
55-59 \\
60-64 \\
65-69 \\
70-74 \\
75-79 \\
80-84 \\
85-89\end{array}$ & $\begin{array}{r}10 \\
40 \\
93 \\
98 \\
95 \\
135 \\
117 \\
90 \\
69 \\
75 \\
83 \\
67 \\
76 \\
73 \\
117 \\
81 \\
71 \\
71 \\
54 \\
65 \\
267 \\
268 \\
203 \\
158 \\
122 \\
145 \\
122 \\
95 \\
96 \\
89 \\
78 \\
61 \\
43 \\
12\end{array}$ & $\begin{array}{r}23 \\
34 \\
103 \\
96 \\
95 \\
127 \\
133 \\
74 \\
77 \\
70 \\
77 \\
74 \\
58 \\
74 \\
107 \\
80 \\
78 \\
95 \\
106 \\
118 \\
459 \\
344 \\
289 \\
204 \\
147 \\
118 \\
77 \\
43 \\
62 \\
62 \\
59 \\
43 \\
30 \\
14\end{array}$ & $\begin{array}{l}0.513 \pm 0.010 \\
0.503 \pm 0.005 \\
0.496 \pm 0.003 \\
0.499 \pm 0.003 \\
0.492 \pm 0.003 \\
0.488 \pm 0.002 \\
0.483 \pm 0.002 \\
0.475 \pm 0.003 \\
0.468 \pm 0.004 \\
0.451 \pm 0.004 \\
0.439 \pm 0.003 \\
0.444 \pm 0.003 \\
0.436 \pm 0.004 \\
0.428 \pm 0.004 \\
0.426 \pm 0.003 \\
0.422 \pm 0.003 \\
0.419 \pm 0.004 \\
0.419 \pm 0.004 \\
0.417 \pm 0.004 \\
0.416 \pm 0.004 \\
0.410 \pm 0.002 \\
0.412 \pm 0.002 \\
0.414 \pm 0.002 \\
0.416 \pm 0.002 \\
0.418 \pm 0.003 \\
0.412 \pm 0.003 \\
0.415 \pm 0.003 \\
0.424 \pm 0.003 \\
0.427 \pm 0.004 \\
0.435 \pm 0.003 \\
0.449 \pm 0.004 \\
0.458 \pm 0.005 \\
0.465 \pm 0.006 \\
0.465 \pm 0.009\end{array}$ & $\begin{array}{l}0.516 \pm 0.008 \\
0.514 \pm 0.006 \\
0.499 \pm 0.003 \\
0.495 \pm 0.003 \\
0.494 \pm 0.003 \\
0.492 \pm 0.003 \\
0.489 \pm 0.003 \\
0.487 \pm 0.004 \\
0.475 \pm 0.004 \\
0.464 \pm 0.003 \\
0.444 \pm 0.004 \\
0.442 \pm 0.003 \\
0.441 \pm 0.005 \\
0.437 \pm 0.004 \\
0.434 \pm 0.003 \\
0.432 \pm 0.004 \\
0.434 \pm 0.003 \\
0.430 \pm 0.003 \\
0.428 \pm 0.003 \\
0.427 \pm 0.002 \\
0.428 \pm 0.001 \\
0.431 \pm 0.002 \\
0.427 \pm 0.002 \\
0.428 \pm 0.002 \\
0.445 \pm 0.003 \\
0.446 \pm 0.003 \\
0.458 \pm 0.004 \\
0.461 \pm 0.005 \\
0.488 \pm 0.005 \\
0.492 \pm 0.004 \\
0.505 \pm 0.005 \\
0.517 \pm 0.007 \\
0.533 \pm 0.007 \\
0.539 \pm 0.011\end{array}$ & $\begin{array}{r}7 \cdot 18 \pm 0 \cdot 08 \\
7 \cdot 72 \pm 0 \cdot 08 \\
8 \cdot 13 \pm 0 \cdot 05 \\
8 \cdot 50 \pm 0 \cdot 05 \\
8 \cdot 62 \pm 0 \cdot 05 \\
8 \cdot 93 \pm 0 \cdot 05 \\
9 \cdot 16 \pm 0 \cdot 05 \\
9 \cdot 49 \pm 0 \cdot 06 \\
9 \cdot 75 \pm 0 \cdot 07 \\
9 \cdot 77 \pm 0 \cdot 08 \\
9 \cdot 92 \pm 0 \cdot 08 \\
10 \cdot 26 \pm 0 \cdot 09 \\
10 \cdot 40 \pm 0 \cdot 10 \\
10 \cdot 80 \pm 0 \cdot 10 \\
11 \cdot 24 \pm 0 \cdot 10 \\
11 \cdot 47 \pm 0 \cdot 11 \\
11 \cdot 61 \pm 0 \cdot 13 \\
11 \cdot 87 \pm 0 \cdot 11 \\
11.92 \pm 0 \cdot 14 \\
11.95 \pm 0 \cdot 13 \\
11 \cdot 99 \pm 0 \cdot 06 \\
12 \cdot 05 \pm 0 \cdot 06 \\
12 \cdot 16 \pm 0 \cdot 07 \\
12 \cdot 17 \pm 0 \cdot 08 \\
12 \cdot 09 \pm 0 \cdot 08 \\
11.94 \pm 0 \cdot 09 \\
12 \cdot 04 \pm 0 \cdot 09 \\
12 \cdot 13 \pm 0 \cdot 11 \\
12 \cdot 17 \pm 0 \cdot 11 \\
12 \cdot 31 \pm 0 \cdot 12 \\
12 \cdot 63 \pm 0 \cdot 12 \\
12 \cdot 97 \pm 0 \cdot 14 \\
13 \cdot 13 \pm 0 \cdot 17 \\
13 \cdot 12 \pm 0 \cdot 33\end{array}$ & $\begin{array}{r}7 \cdot 17 \pm 0.09 \\
7 \cdot 61 \pm 0.09 \\
7 \cdot 95 \pm 0.05 \\
8 \cdot 18 \pm 0.05 \\
8 \cdot 31 \pm 0.05 \\
8 \cdot 68 \pm 0.05 \\
8 \cdot 84 \pm 0.05 \\
9 \cdot 11 \pm 0.08 \\
9 \cdot 37 \pm 0.07 \\
9 \cdot 55 \pm 0.08 \\
9 \cdot 58 \pm 0.08 \\
9 \cdot 84 \pm 0.09 \\
10.08 \pm 0 \cdot 11 \\
10 \cdot 50 \pm 0.09 \\
10 \cdot 81 \pm 0.09 \\
10 \cdot 85 \pm 0 \cdot 10 \\
10 \cdot 89 \pm 0 \cdot 10 \\
10 \cdot 87 \pm 0.09 \\
10 \cdot 88 \pm 0.09 \\
10.92 \pm 0.08 \\
11.09 \pm 0.04 \\
11 \cdot 12 \pm 0.05 \\
11.09 \pm 0.05 \\
11 \cdot 15 \pm 0.07 \\
11.41 \pm 0.09 \\
11.44 \pm 0.09 \\
11.65 \pm 0 \cdot 11 \\
11 \cdot 72 \pm 0 \cdot 14 \\
12 \cdot 10 \pm 0 \cdot 15 \\
11 \cdot 84 \pm 0 \cdot 10 \\
12.35 \pm 0 \cdot 10 \\
12.03 \pm 0 \cdot 17 \\
12 \cdot 28 \pm 0 \cdot 12 \\
12.39 \pm 0 \cdot 33\end{array}$ \\
\hline
\end{tabular}

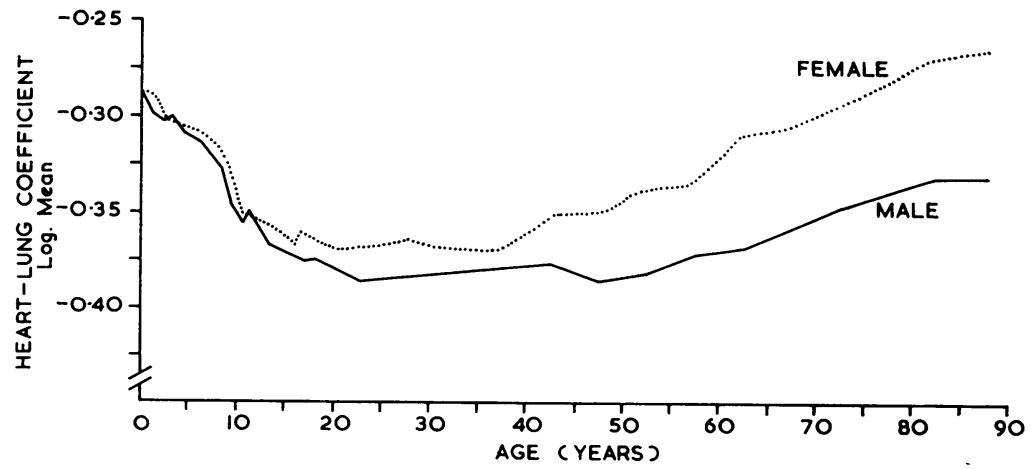

FIG. 1-Logarithms of means of heart-lung coefficient by age and sex. 
TABLE II

The Heart-Lung Coefficient by Age and Sex Showing 95 per cent (2 Standard Deviation) Limits

\begin{tabular}{|c|c|c|c|c|}
\hline \multirow{2}{*}{$\begin{array}{c}\text { Age-group } \\
\text { (yrs.) }\end{array}$} & \multicolumn{2}{|c|}{ Male subjects } & \multicolumn{2}{|c|}{ Female subjects } \\
\hline & $-2 \times$ S. D. & $+2 \times S . D$. & $-2 \times$ S. D. & $+2 \times$ S. D. \\
\hline $\begin{array}{r}<1 \\
1 \\
2 \\
3 \\
4 \\
5 \\
6 \\
7 \\
8 \\
9 \\
10 \\
11 \\
12 \\
13 \\
14 \\
15 \\
16 \\
17 \\
18 \\
19 \\
20-24 \\
25-29 \\
30-34 \\
35-39 \\
40-44 \\
45-49 \\
50-54 \\
55-59 \\
60-64 \\
65-69 \\
70-74 \\
75-79 \\
80-84 \\
85-89\end{array}$ & $\begin{array}{l}0.447 \\
0.443 \\
0.436 \\
0.446 \\
0.438 \\
0.430 \\
0.429 \\
0.411 \\
0.408 \\
0.381 \\
0.377 \\
0 \cdot 388 \\
0 \cdot 362 \\
0.364 \\
0.360 \\
0.360 \\
0.349 \\
0.357 \\
0.355 \\
0.354 \\
0.346 \\
0.348 \\
0.352 \\
0.354 \\
0.358 \\
0.346 \\
0.357 \\
0.360 \\
0.355 \\
0.376 \\
0.385 \\
0.380 \\
0.391 \\
0.401\end{array}$ & $\begin{array}{l}0.579 \\
0.563 \\
0.556 \\
0.554 \\
0.546 \\
0.546 \\
0.537 \\
0.539 \\
0.528 \\
0.521 \\
0.501 \\
0.500 \\
0.510 \\
0.492 \\
0.492 \\
0.484 \\
0.489 \\
0.481 \\
0.479 \\
0.478 \\
0.474 \\
0.476 \\
0.476 \\
0.478 \\
0.478 \\
0.478 \\
0.473 \\
0.488 \\
0.499 \\
0.496 \\
0.513 \\
0.536 \\
0.539 \\
0.529\end{array}$ & 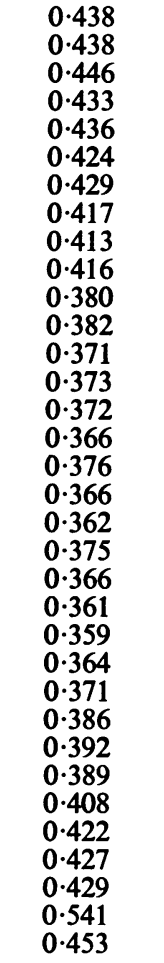 & $\begin{array}{l}0.594 \\
0.590 \\
0.554 \\
0.557 \\
0.552 \\
0.560 \\
0.549 \\
0.557 \\
0.537 \\
0.512 \\
0.508 \\
0.502 \\
0.511 \\
0.501 \\
0.496 \\
0.498 \\
0.492 \\
0.494 \\
0.494 \\
0.479 \\
0.490 \\
0.501 \\
0.495 \\
0.492 \\
0.519 \\
0.506 \\
0 \cdot 524 \\
0.533 \\
0.568 \\
0.562 \\
0.583 \\
0.605 \\
0.615 \\
0.625\end{array}$ \\
\hline
\end{tabular}

are $0.513,0.416$, and 0.416 respectively. As age advances further there is no comparable increase with that noted for women in the fifth decade. Indeed, the men show a slight decline in the late 40 's to an average of 0.412 . In men an increase noted at 55-59 years with a mean of 0.424 continues thereafter to a maximum of 0.465 at $85-89$ years.

Throughout the entire age range the absolute variability of the heart-lung coefficient varies between 0.027 and 0.039 for male and between 0.024 and 0.044 for female subjects, while the relative variability is moderate with the highest figure at 8.6 and the lowest at 5.4 for male subjects. The corresponding figures for female subjects are $8 \cdot 5$ and $5 \cdot 1$.

Transverse Diameter of Heart. The trend of the male heart diameter means indicates that the most rapid increase in heart size is from birth to 3 years; that this is followed by a slight lag in the fourth year and further rapid change up to 17 years with a stationary phase at 9 years. Continued much slower increase in the heart diameter occurs from an average of $11.9 \mathrm{~cm}$. at 17 years to $12.2 \mathrm{~cm}$. at 35-39 years. A slight decline to $11.9 \mathrm{~cm}$. at $45-49$ years gives way to a regular rise which attains a maximum of $13.1 \mathrm{~cm}$. in the ninth decade. The respects in which the female heart diameter means differ from those of the male are that at all ages the averages of the women are less than the corresponding averages of the men; the stationary phase at 10 years is one year later than that observed for boys; the rapid increase in heart size in childhood ceases at 14 years; and, since 
there is no comparable decline in the fifth decade with that noted for men, there is a fairly regular increase in the average heart diameter from $11.2 \mathrm{~cm}$. at $35-39$ years to $12.4 \mathrm{~cm}$. in the latter half of the ninth decade.

The absolute variability for the transverse diameter of the heart is similar for the sexes, and in adult life the absolute variability of approximately 1.0 is about twice that noted in the earliest years of life excluding infancy. For the pre-school child the absolute variability is greatest in infancy.

The relative variability for the transverse diameter of the heart is similar for the sexes and is moderate. It is relatively high in infancy, while in adult life it is never greater than $\mathbf{9 . 4}$ for men and 9.9 for women.

\section{Discussion}

In this study the relative variability of the heart-lung coefficient is somewhat less than that of the transverse diameter of heart, and both are moderate. In terms of scatter of the observations which form a frequency distribution, the heart-lung coefficient is to be preferred as an index of heart size, and is a ratio with a most desirable variability. This supports the statement of Kerley (1950) that the heart-lung coefficient is a fairly reliable guide to heart size, since the shape of the heart is to a large extent dependent on the shape of the chest. It is, therefore, a cause for concern that White (1944) is critical of the heart-lung coefficient on the grounds of excessive variability. Furthermore, the transverse heart diameter is favoured by Hodges and Eyster (1926), Bedford and Treadgold (1931), Bainton (1932) and others. I assume that much unjustified criticism of the heart-lung coefficient is due to the absence of a standardized method of measuring the transverse chest diameter, and failure to consider the influence of excessive obesity. The transverse chest diameter is an example of a variable that has been described in earlier publications in several different ways. This is detrimental to the advancement of knowledge especially in the comparative field.

Danzer (1919), without stating the age or sex of his cases, recorded a range for the heart-lung coefficient of 39 to 50 per cent with an average value of 45 per cent. This oversimplifies the problem. Age is an important influencing variable and for men the 0.50 upper limit of Danzer (1919) is too low in childhood and over the age of 65 years, and somewhat high for the age range between childhood and 69 years where 0.48 is more appropriate. With women the 0.50 of Danzer (1919) applies between 14 and 39 years, but is inadequate to meet the higher heart-lung coefficient values of children and of women over 39 years.

The results presented show a slight diminution in the magnitude of the mean heart diameter in the fifth decade for men. Tirman and Hamilton (1952) make no comment upon a similar decline that they record. This fall in the fifth decade may be due to factors other than chance occurrence. Consequently the regular increase in the transverse heart diameter with age of $1 \mathrm{~mm}$. per decade predicted by Hodges and Eyster (1926) is to be accepted with reserve. Ungerleider and Clark's (1939) opinion that no correction for age between 15 and 50 years, indeed, at any age, is necessary for the transverse heart diameter is misleading particularly in older years. The present analysis shows a significant sex difference with the transverse heart diameter means of women increasing in value from the earlier part of the fifth decade. Tirman and Hamilton (1952) observed the start of the upward trend in the transverse heart diameter means in elderly men and postulated that it was possibly a phenomenon of advanced years. My results indicate that the increase in heart diameter size for men commences relatively early towards the end of the sixth decade and continues regularly thereafter.

\section{SUMMARY}

Normal standards for the heart-lung coefficient and transverse diameter of the heart are presented with reference to 3339 male and 3650 female subjects aged from infancy to 89 years. The data do not apply over the age of 54 years to people more than 24 per cent over ideal weight as estimated from Anderson's nomogram (1948). 
The significant changes that occur in the heart-lung coefficient and the transverse diameter of heart with age preclude the use of a constant value for either attribute as an upper limit of normality throughout life.

The relative variabilities of the heart-lung coefficient and the transverse diameter of heart are moderate and throughout life vary approximately between 5.5 and 8.5 and between 6 and 10 respectively.

The work described in this paper is included in a Ph.D. thesis (Glasgow University, 1962).

Acknowledgement is made to the Secretary of State for Scotland for a grant provided on the recommendation of the Advisory Committee on Medical Research.

\section{REFERENCES}

Anderson, A. B. (1948). In The Practice of Endocrinology, ed. R. Greene, p. 319. Eyre and Spottiswoode, London. Bainton, J. H. (1932). The transverse diameter of the heart. Amer. Heart J., 7, 331.

Bedford, D. E., and Treadgold, H. A. (1931). The size of the healthy heart and its measurement. Lancet, 2, 836.

Cowan, N. R. (1959). The heart lung coefficient in older people. Brit. Heart J., $21,238$.

Danzer, C. S. (1919). The cardiothoracic ratio: an index of cardiac enlargement. Amer. J. med. Sci., 157, 513.

Hodges, F. J., and Eyster, J. A. E. (1926). Estimation of transverse cardiac diameter in man. Arch. intern. Med., 37, 707 .

Kerley, P. (1950). In A Text-Book of X-ray Diagnosis, 2nd ed., ed. S. C. Shanks and P. Kerley, Vol. 2, p. $19 . \quad$ Lewis, London.

Tirman, W. S., and Hamilton, J. B. (1952). Aging in apparently normal men. IV. The roentgenologic appearance of the thorax and thoracic organs. J. Geront., 7, 384.

Ungerleider, H. E., and Clark, C. P. (1939). A study of the transverse diameter of the heart silhouette with prediction table based on the teleoroentgenogram. Amer. Heart J., 17, 92.

White, P. D. (1944). Heart Disease, 3rd ed., p. 127. Macmillan, New York. 